\begin{tabular}{|c|c|}
\hline Title & Highly efficient enzymatic synthesis of 3'-deoxy apionucleic acid (apioNA) having the four natural nucleobases \\
\hline Author(s) & Kataoka, Mayumi; Kouda, Y asuo; Sato, Kousuke; Minakawa, Noriaki; Matsuda, A kira \\
\hline Citation & $\begin{array}{l}\text { Chemical Communications, } 47(30), 8700-8702 \\
\text { https://doi.org/10.1039/c1cc12980e }\end{array}$ \\
\hline Issue Date & 2011-08-14 \\
\hline Doc URL & http:/hdl.handle.net/2115/49422 \\
\hline Rights & Chem. Commun., 2011, 47, 8700-8702 - Reproduced by permission of The Royal Society of Chemistry (RSC) \\
\hline Type & article (author version) \\
\hline Additional Information & There are other files related to this item in HUSCAP. Check the above URL. \\
\hline File Information & CC47-30_8700-8702.pdf \\
\hline
\end{tabular}

Instructions for use 


\title{
Highly efficient enzymatic synthesis of 3'-deoxyapionucleic acid (apioNA) having the four natural nucleobases
}

\author{
Mayumi Kataoka, Yasuo Kouda, Kousuke Sato, Noriaki Minakawa and Akira Matsuda* \\ Received (in $X X X, X X X)$ Xth $X X X X X X X X X 20 X X$, Accepted Xth $X X X X X X X X X 20 X X$ \\ DOI: 10.1039/b000000x
}

The synthesis of the 3'-deoxyapionucleoside 3"-triphosphates (apioNTPs) having the four natural nucleobases and their enzymatic incorporation into a DNA-DNA primer-template have been tried. Therminator DNA polymerase was shown to 10 incorporate these apioNTPs effectively giving 43mer DNAapioNA chimera.

Since nucleic acid aptamers are relatively easily isolated from iterative rounds of selection for binding to various targets with high affinities and selectivities, they are expected to be 15 not only useful therapeutic agents but also biological tools. ${ }^{1}$ Therapeutic aptamers can act as nucleic acid antibodies against protein targets; ${ }^{2}$ they can also transport oligonucleotide therapeutic agents into target cells through receptor-mediated endocytosis. ${ }^{3}$ However, because the 20 unmodified oligonucleotides selected are spontaneously degraded before reaching the target, time-consuming postselection modifications for stabilizing them against nucleases abundant in biological fluids are usually required. ${ }^{4}$ Although isolation of fully-modified aptamers during the selection ${ }_{25}$ process is desired, it is nevertheless difficult to achieve because of the high substrate specificity of DNA/RNA polymerases required to incorporate modified nucleoside triphosphates, which are necessary to impart nucleaseresistance after incorporation into the oligonucleotides. ${ }^{5}$

30 Therefore, the development of a system that incorporates nuclease-resistant chemically modified nucleoside triphosphates having four natural nucleobases still remains a challenge.

Recently, $\alpha$-L-threofuranosyl nucleoside 3'-triphosphates 35 (tNTPs) have been incorporated into a DNA-DNA primertemplate by DNA polymerases, such as Therminator DNA polymerase, to afford DNA-TNA $\left[\alpha\right.$-L-threose- $\left(3^{\prime} \rightarrow 2^{\prime}\right)$ nucleic acid] chimeras up to a $75 \mathrm{mer}(25 \mathrm{mer}$ DNA $+50 \mathrm{mer}$ TNA) with $>20 \%$ yield within $24 \mathrm{~h}$, although the chemical 40 structures of tNTPs are rather different from those of the natural 2'-deoxyribonucleoside 5 '-triphosphates (dNTPs). ${ }^{6}$ Other sugar-modified nucleoside triphosphates such as $\mathrm{GNA}^{7}$, $\mathrm{FNA}^{8}, \mathrm{LNA} / \mathrm{BNA}^{9}$ and HNA ${ }^{10}$, were synthesized and their

Faculty of Pharmaceutical Sciences, Hokkaido University, Sapporo, Hokkaido 060-0812, Japan. E-mail: matuda@pharm.hokudai.ac.jp; Fax: (+81) 11-706-4980; Tel: (+81) 11-706-3228

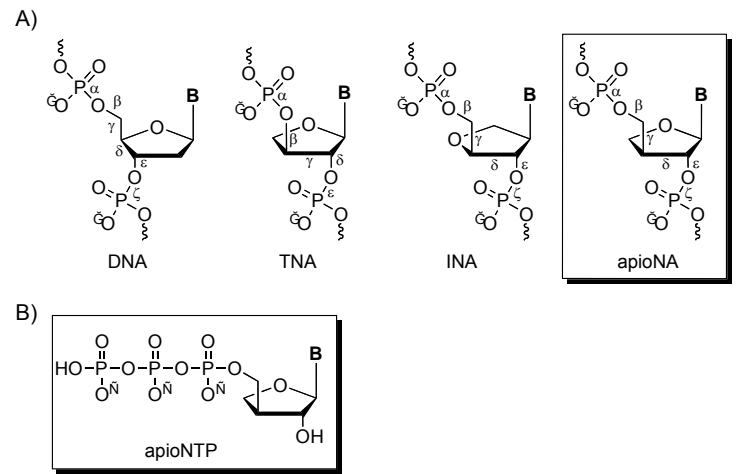

Figure 1. Structures of DNA, TNA, INA, apioNA (A) and apioNTP (B).

45 incorporation into DNA by DNA polymerases was also investigated. These results have inspired us to further investigate other sugar-modified nucleoside triphosphates, which could be incorporated into the desired length of oligonucleotides, since oligonucleotides containing these so sugar-modified nucleosides would be expected to be nucleaseresistant. Although TNAs are linked together through their 3'and 2'-hydroxyl groups by a phosphodiester bond and their repeating unit consists of a backbone (5-bonds) one atom shorter than the natural DNA phosphodiester backbone (655 bonds) (Figure 1), tNTPs acted as substrates of DNA polymerases, but not well enough to be able to isolate aptamers. Therefore, we designed two new candidates that could be inserted and elongated much more efficiently by DNA polymerases. These are 2'-deoxy-2'-isonucleoside 5'60 triphosphates (iNTPs) and 3'-deoxyapionucleoside 3"triphosphates (apioNTPs), both of which have a 6-bond phosphodiester backbone similar to DNA although they are regioisomers. We and others have examined the incorporation of iNTPs into DNA by DNA polymerases. ${ }^{11}$ However, the ${ }_{65}$ shape of the iNTPs and local conformational changes of the duplex containing 2'-deoxy-2'-isonucleosides disrupted the elongation reaction to give the full length DNA-INA product. Therefore, in this paper, we examined the enzymatic insertion and elongation reactions of apioNTPs, which are one-carbon 70 longer homologues of the tNTPs at the 3 ' position.

The synthesis of the 3'-deoxyapionucleosides having the four natural nucleobases was carried out using the previous $\operatorname{methods}^{12}$ with a slight modification, and their 3"triphosphates (apioNTPs) were prepared (see supporting 
A)

5'-FAM-d(GACGGAATATAAGCTGGTGG)-3'

3' -d(CTGCCTTATATTCGACCACCTGCAGCA)-5' apioNTPs DNA polymerase

5'-FAM-d(GACGGAATATAAGCTGGTGGACGTCGT)-3'

3' -d(CTGCCTTATATTCGACCACCTGCAGCA)-5'
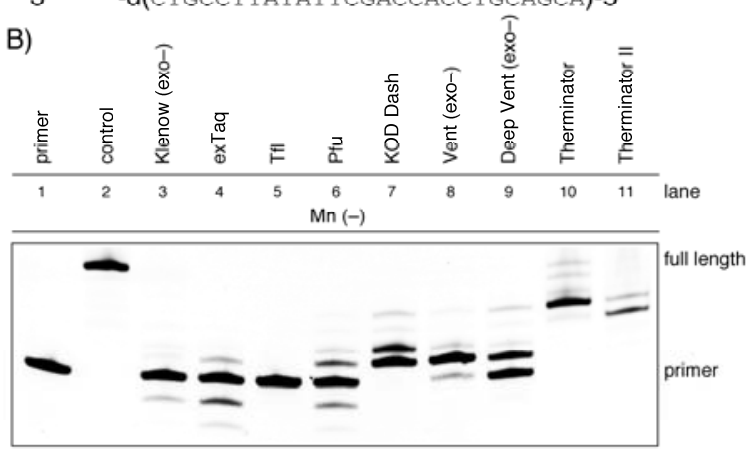

C)

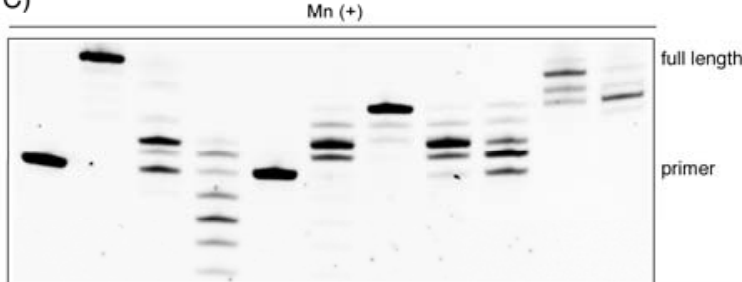

Figure 2. A) Sequence of the primer-template complex and the apioNA elongation product. Elongated apioNA is shown in bold letters. B) Primer extension experiments: The primer was 5'-FAM labeled and annealed with the DNA template. Polymerization reactions were performed with $50.8 \mu \mathrm{M}$ primer-template and $200 \mu \mathrm{M}$ all four apioNTPs by incubating for $1 \mathrm{~h}$ with $1.0 \mu \mathrm{L}$ of DNA polymerase [Klenow (exo-) $0.9 \mathrm{U} / \mu \mathrm{L}$, exTaq 0.5 $\mathrm{U} / \mu \mathrm{L}, \mathrm{Tfl} 0.5 \mathrm{U} / \mu \mathrm{L}$, Pfu $0.25 \mathrm{U} / \mu \mathrm{L}$, KOD Dash $0.25 \mathrm{U} / \mu \mathrm{L}$, Vent (exo-) $0.2 \mathrm{U} / \mu \mathrm{L}$, Deep Vent (exo-) $0.2 \mathrm{U} / \mu \mathrm{L}$, Therminator $0.2 \mathrm{U} / \mu \mathrm{L}$, and Therminator II $0.2 \mathrm{U} / \mu \mathrm{L}$ ] under conditions optimal for each enzyme.

10 information). In the presence of all four apioNTPs, the primer extension reaction of a 5'-FAM labeled DNA primer (20mer) and a DNA template (27mer) was examined using 9 different DNA polymerases (Figure 2). As shown in Figure 2B, most of the DNA polymerases were unable to elongate the primer with 15 the apioNTPs, but Therminator and Therminator II DNA polymerases incorporated three or four apioNTPs (lanes 10 and 11$). \mathrm{Mn}^{2+}$ is known to relax the substrate specificity of many DNA polymerases, possible by allowing it to enhance its binding to the $\beta$ - and $\gamma$-phosphates of the dNTPs. ${ }^{13}$ 20 Addition of $\mathrm{Mn}^{2+}(1.25 \mathrm{mM})$ to the enzyme reaction mixture was found to show a dramatic effect in the elongation reaction by the polymerase (Figure 2C). Klenow (exo-), Pfu, KOD Dash, Vent (exo-), Deep Vent (exo-) and Therminator (lanes $3,6-10)$ gave longer elongation product than $\mathrm{Mn}(-)$ reactions 25 (Figure 2B), and especially Therminator revealed full length 1 product as a major product. Therefore, reaction conditions of Therminator were optimized relative to the reaction temperatures and the enzyme concentrations (Figures 3 and $\mathrm{S} 1)$. The reaction temperature sometimes influences the 30 primer extension reactions for modified triphosphates. ${ }^{14,6 \mathrm{~d}}$ Therefore, we investigated the reaction under lower temperatures than those optimized in the presence of $\mathrm{Mn}^{2+}$. Interestingly full length bands were detected when the reactions were performed at 64 and $54{ }^{\circ} \mathrm{C}$ (lanes 4 and 5, 35 respectively), but not at $74{ }^{\circ} \mathrm{C}$. At even lower temperatures, e.g., 44 and $34{ }^{\circ} \mathrm{C}$, the elongation reaction was accelerated to afford the full length product as essentially one band (lanes 6 and 7). The enzyme concentration was also optimized in Figure S1, the higher concentration of Therminator DNA 40 polymerase $(0.2 \mathrm{U} / \mu \mathrm{L} ; 1.7 \mu \mathrm{M})$ was needed for efficient elongation of apioNA.

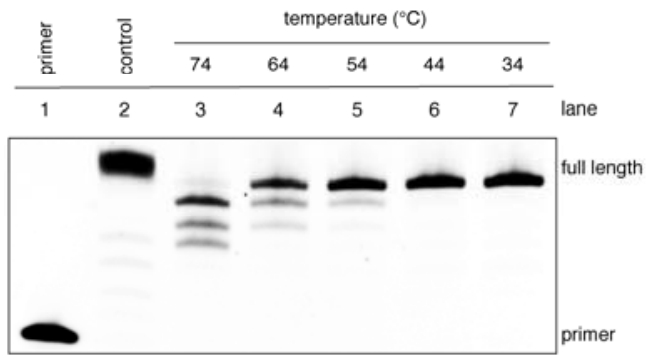

Figure 3. Primer extension reactions with various reaction temperatures The reactions were performed with same reaction conditions in general method (see supporting information) except for reaction temperature; 74, $4564,54,44$, and $34{ }^{\circ} \mathrm{C}$ (lanes 3-7). Lane 1; primer, Lane 2; control.

Since the mobility of the full length bands was slightly different from that of its DNA counterpart on their denaturing polyacrylamide gel when the reactions were performed using dNTPs or apioNTPs (Figure 3), the full length band (27mer) 50 from the apioNTPs was confirmed by MALDI-TOF mass spectroscopy at $\mathrm{m} / \mathrm{z} 8401.8$ (Figure S2). Consequently, we found the optimized primer extension reaction conditions, which were $0.8 \mu \mathrm{M}$ primer-template duplex and $1.7 \mu \mathrm{M}(0.2$ $\mathrm{U} / \mu \mathrm{L}$ ) Therminator DNA polymerase in the ThermoPol buffer ${ }_{55}$ containing $1.25 \mathrm{mM} \mathrm{MnCl}_{2}$ at $44{ }^{\circ} \mathrm{C}$ for $1 \mathrm{~h}$.

In order to evaluate the substrate ability of dNTP and apioNTP quantitatively, we determined the kinetic parameters $\left(K_{\mathrm{m}}=\right.$ the Michaelis constant, $V_{\max }=$ the maximum rate of the enzyme reaction and $V_{\max } / K_{\mathrm{m}}=$ the insertion efficiency) of ${ }_{60}$ every triphosphate at various concentrations in the presence or absence of $\mathrm{Mn}^{2+}$, and the data are shown in Table 1 . In the absence of $\mathrm{Mn}^{2+}$, the relative efficiency of incorporation of dTTP into the primer was about twice that of the apioTTP (100 vs 46$)$. The difference is presumably a reflection of their ${ }_{65} K_{\mathrm{m}}$ values $(0.022$ vs $0.058 \mu \mathrm{M})$, but not that of their $V_{\max }$ values $\left(7.4\right.$ vs $\left.9.4 \% \cdot \mathrm{min}^{-1}\right)$. Other triphosphates showed a similar effect with thymine nucleotides, namely relatively larger differences in the $K_{\mathrm{m}}$ values (1.5-3.5 times) and smaller differences in the $V_{\max }$ values (1.2-1.3 times) between dNTPs 70 and apioNTPs, respectively. These quantitative analyses revealed that Therminator incorporated the apioNTPs into the DNA/DNA primer/template duplex with 2-5 times lower relative efficiency than the dNTPs. The effect of the addition of $\mathrm{Mn}^{2+}$ was next investigated by using single nucleotide 75 insertion reactions. As can be seen from Table 1, the polymerase incorporated apioTTP with almost the same efficiency in the presence or absence of $\mathrm{Mn}^{2+}$ (relative efficiency; 48 vs 46), and also with similar $K_{\mathrm{m}}$ ( 0.086 vs 0.058 $\mu \mathrm{M})$ and $V_{\max }\left(14.0\right.$ vs $\left.9.4 \% \cdot \mathrm{min}^{-1}\right)$ values. Other nucleotides 80 showed similar results with little difference in $K_{\mathrm{m}}(0.4-1.6$ times) and $V_{\max }$ (0.4-1.5 times) values. Therefore, the addition of $\mathrm{Mn}^{2+}$ to the enzyme reaction mixture did not show any dramatic effects on the single nucleotide insertion reaction of the apioNTP.

85 It is obvious that the elongation reactions of the apioNTPs 
Table 1. The kinetic parameters of dNTPs and apioNTPs in the absence

\begin{tabular}{cccccc}
\hline \multicolumn{2}{c}{$\operatorname{NTP}\left(\mathrm{MnCl}_{2}\right)$} & \multicolumn{1}{c}{$K_{\mathrm{m}}(\mu \mathrm{M})$} & $\begin{array}{c}V_{\max } \\
\left(\% \cdot \mathrm{min}^{-1}\right)\end{array}$ & $\begin{array}{c}V_{\max } / K_{\mathrm{m}} \\
\left(\% \cdot \mathrm{min}^{-1} \cdot \mathrm{M}^{-1}\right)\end{array}$ & $\begin{array}{c}\text { relative } \\
\text { efficiency }\end{array}$ \\
\hline dTTP & $(-)$ & $0.022 \pm 0.0075$ & $7.4 \pm 1.7$ & $3.5 \times 10^{8}$ & 100 \\
\multirow{2}{*}{ apioTTP } & $(-)$ & $0.058 \pm 0.025$ & $9.4 \pm 1.0$ & $1.6 \times 10^{8}$ & 46 \\
& $(+)$ & $0.086 \pm 0.020$ & $14.0 \pm 1.9$ & $1.7 \times 10^{8}$ & 48 \\
\hline \multirow{2}{*}{ dCTP } & $(-)$ & $0.040 \pm 0.012$ & $5.9 \pm 0.74$ & $1.5 \times 10^{8}$ & 100 \\
\multirow{2}{*}{ apioCTP } & $(-)$ & $0.090 \pm 0.020$ & $4.8 \pm 1.4$ & $5.4 \times 10^{7}$ & 35 \\
& $(+)$ & $0.063 \pm 0.0033$ & $4.5 \pm 1.4$ & $7.1 \times 10^{7}$ & 46 \\
\hline \multirow{2}{*}{ dATP } & $(-)$ & $0.022 \pm 0.0078$ & $7.1 \pm 0.82$ & $3.4 \times 10^{8}$ & 100 \\
\multirow{2}{*}{ apioATP } & $(-)$ & $0.078 \pm 0.0015$ & $5.5 \pm 0.54$ & $7.1 \times 10^{7}$ & 21 \\
& $(+)$ & $0.031 \pm 0.007$ & $2.4 \pm 0.14$ & $8.0 \times 10^{7}$ & 24 \\
\hline \multirow{2}{*}{ dGTP } & $(-)$ & $0.036 \pm 0.012$ & $8.3 \pm 1.6$ & $2.4 \times 10^{8}$ & 100 \\
\multirow{2}{*}{ apioGTP } & $(-)$ & $0.047 \pm 0.022$ & $6.1 \pm 0.92$ & $1.6 \times 10^{8}$ & 69 \\
& $(+)$ & $0.075 \pm 0.046$ & $5.8 \pm 0.71$ & $1.3 \times 10^{8}$ & 56 \\
\hline
\end{tabular}

or presence of $\mathrm{Mn}^{2+}$ with Therminator DNA polymerase $\mathrm{e}^{[\mathrm{a}]}$

[a] Assay conditions: Reactions were initiated by adding 1 / $\mathrm{L}$ of a dNTP or apioNTP solution to 9 ( $\mathrm{L}$ of the reaction mixture containing a $0.8 \int \mathrm{M}$ 5 5'-FAM labeled primer-template complex, $42.5 \mathrm{nM}(0.005 \mathrm{U} /[\mathrm{L})$

Therminator DNA polymerase in the ThermoPol buffer (see supporting information) in the absence or presence of $1.25 \mathrm{mM} \mathrm{MnCl}_{2}$ incubating for $3 \mathrm{~min}$ at $74^{\circ} \mathrm{C}$, and quenching with the addition of 10 / $\mathrm{L}$ loading buffer.

by Therminator were evidently accelerated in the presence of ${ }_{10} \mathrm{Mn}^{2+}$ as shown in Figure 2. Therefore, we hypothesized that $\mathrm{Mn}^{2+}$ influenced the elongation reaction after incorporation of several apionucleotides into the DNA primer. To examine this hypothesis, a chimera oligonucleotide primer (5'-FAM 20mer DNA +4 mer apioNA) was synthesized by the usual 15 phosphoramidite method except for the coupling time of the apioNA (see supporting information). Single nucleotide insertion reactions using apioATP were then performed using a steady-state method in the presence or absence of $\mathrm{Mn}^{2+}$. Although $V_{\max }$ shows almost the same values $(3.3$ vs ${ }_{20} 3.0 \% \cdot \mathrm{min}^{-1}$ ), the $K_{\mathrm{m}}$ values were different by one order of magnitude with or without addition of $\mathrm{Mn}^{2+}$ (0.044 vs 0.403 $\mu \mathrm{M})$ as shown in Table 2. Consequently, the relative efficiency increased over 10 fold when $\mathrm{Mn}^{2+}$ was added to the reaction mixture.

25 Table 2. The kinetic parameters of apioATP in the absence or presence of $\mathrm{Mn}^{2+}$ with Therminator DNA polymerase $\mathrm{e}^{[\mathrm{a}]}$

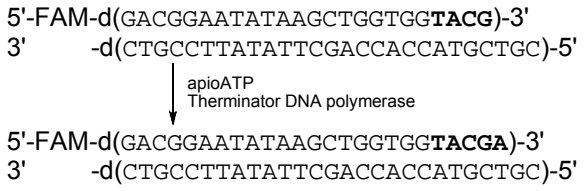

\begin{tabular}{|c|c|c|c|c|}
\hline $\operatorname{NTP}\left(\mathrm{MnCl}_{2}\right)$ & $K_{\mathrm{m}}(\mu \mathrm{M})$ & $\begin{array}{c}V_{\max } \\
\left(\% \cdot \min ^{-1}\right)\end{array}$ & $\begin{array}{c}V_{\max } / K_{m} \\
\left(\% \cdot m^{-1} \cdot M^{-1}\right)\end{array}$ & $\begin{array}{c}\text { relative } \\
\text { efficiency }\end{array}$ \\
\hline \multirow{2}{*}{ apioATP $\begin{array}{c}(-) \\
(+)\end{array}$} & $0.403 \pm 0.014$ & $3.0 \pm 0.11$ & $7.4 \times 10^{6}$ & 100 \\
\hline & $0.044 \pm 0.007$ & $3.3 \pm 0.16$ & $7.5 \times 10^{7}$ & 1014 \\
\hline
\end{tabular}

[a] Assay conditions: The reactions were performed with the same reaction conditions described in Table 1 except for $1.7 / \mathrm{M}\left(0.2 \mathrm{U} / \int \mathrm{L}\right)$ Therminator DNA polymerase.

30 Finally, a longer elongation polymerase reaction by Therminator was carried out using a 21 mer DNA primer and a 43 mer DNA template. In this case, the reactions under lower temperature are also effective for longer elongation in the presence of $\mathrm{Mn}^{2+}$ (Figure S3). Consequently, a longer 35 elongation polymerase reaction ( $22 \mathrm{mer}$ apioNA elongation) at lower temperatures, such as 44 and $34{ }^{\circ} \mathrm{C}$, would appear to be more efficient for full length product formation by Therminator DNA polymerase containing $1.25 \mathrm{mM} \mathrm{MnCl}_{2}$ within $1 \mathrm{~h}$.

40 In summary, we have synthesized apioNTPs, the onecarbon longer homologue of the $\alpha$-L-threofuranosyl nucleoside 3 '-triphosphates (tNTPs) at the 3'-position having the four natural bases (T, C, A and G) and also identified Therminator DNA polymerase as a polymerase that is capable 45 of highly efficient enzymatic apioNA synthesis. Moreover we found that $\mathrm{Mn}^{2+}$ and lower temperatures are important for longer elongation of apioNA but are not required for a single nucleotide insertion reaction into a DNA-DNA duplex (Figure 3 and Table 1). A longer elongation polymerase reaction ${ }_{50}(22 \mathrm{mer}$ apioNA elongation) has also been achieved at 34 or $44{ }^{\circ} \mathrm{C}$ within $1 \mathrm{~h}$. Therefore, the apioNTPs are some of the most effective sugar-modified triphosphates for enzymatic polymerization by DNA polymerase. Studies of apioNA templated apioNA synthesis by Therminator DNA polymerase 55 are now under investigation.

\section{Notes and references}

$\uparrow$ Electronic Supplementary Information (ESI) available: Experimental details of synthesis, ${ }^{1} \mathrm{H}$ and ${ }^{31} \mathrm{P}$ NMR of apioNTPs, ODN synthesis, elongation reactions, single nucleotide insertion reactions, and MALDI60 TOF mass spectrum of full length $27 \mathrm{mer}$ elongated product. See DOI: $10.1039 / \mathrm{b} 000000 \mathrm{x} /$

1 D. H. J. Bunka, P. G. Stockley, Nat. Rev. Microbiol. 2006, 4, 588.

2 (a) A. D. Keefe, S. Pai, A. Ellington, Nat. Rev. Drug Discovery 2010 , 65 9, 537; (b) P. R. Bouchard, R. M. Hutabarat, K. M. Thompson, Annu. Rev. Pharmacol. Toxicol. 2010, 50, 237.

3 (a) N. S. Que-Gewirth, B. A. Sullenger, Gene Ther. 2007, 14, 283; (b) A. C. Yan, M. Levy, RNA Biol. 2009, 6, 316.

4 A. D. Keefe, S. T. Cload, Curr. Opin. Chem. Biol. 2008, 12, 448.

705 (a) P. E. Burmeister, S. D. Lewis, R. F. Silva, J. R. Preiss, L. R. Horwitz, P. S. Pendergrast, T. G. McCauley, J. C. Kurz, D. M. Epstein, C. Wilson, A. D. Keef, Chem. Biol. 2005, 12, 25; (b) N. Minakawa, M. Sanji, Y. Kato, A. Matsuda, Bioorg. Med. Chem. 2008, 16, 9450 .

756 (a) J. C. Chaput, J. W. Szostak, J. Am. Chem. Soc. 2003, 125, 9274 ; (b) A. Horhota, K. Zou, J. K. Ichida, B. Yu, L. W. McLaughlin, J. W. Szostak, J. C. Chaput, J. Am. Chem. Soc. 2005, 127, 7427; (c) V. Kempeneers, K. Vastmans, J. Rozenski, P. Herdewijn, Nucleic Acids Res. 2003, 31, 6221; (d) J. K. Ichida, K. Zou, A. Horhota, B. Yu, L.

80 W. McLaughlin, J. W. Szostak, J. Am. Chem. Soc. 2005, 127, 2802.

7 (a) A. T. Horhota, J. W. Szostak, L. W. McLaughlin, Org. Lett. 2006, 8, 5345; (b) J. J. Chen, C.-H. Tsai, X. Cai, A. T. Horhota, L. W. McLaughlin, J. W. Szostak, PLoS ONE 2009, 4, 1.

8 B. D. Heuberger, C. Switzer, J. Am. Chem. Soc. 2008, 130, 412.

${ }_{85} 9$ (a) R. N. Veedu, B. Vester, J. Wengel, ChemBioChem 2007, 8, 490; (b) R. N. Veedu, B. Vester, J. Wengel, J. Am. Chem. Soc. 2008, 130, 8124; (c) R. N. Veedu, B. Vester, J. Wengel, Nucleosides Nucleotides Nucleic Acids 2007, 26, 1207.

10 (a) K. Vastmans, S. Pochet, A. Peys, L. Kerremans, A. van Aerschot, C. Hendrix, P. Marlière, P. Herdewijn, Biochemistry 2000, 39, 12757; (b) M. Renders, M. Abramov, M. Froeyen, P. Herdewijn, Chem. Eur. J. 2009, 15, 5463.

11 (a) C. Jiang, B. Li, Z. Guan, Z. Yang, L. Zhang, L. Zhang, Bioorg. Med. Chem. 2007, 15, 3019; (b) T. Ogino, K. Sato, A. Matsuda, ChemBioChem 2010, 11, 2597.

12 D. Z. Jin, S. H. Kwon, H. R. Moon, P. Gunaga, H. O. Kim, D.-K. Kim, M. W. Chun, L. S. Jeong, Bioorg. Med. Chem. 2004, 12, 1101.

13 (a) R. C. Cadwell, G. F. Joyce, PCR Methods Appl. 1992, 2, 28; (b) S. Tabor, C. C. Richardson, Proc. Natl. Acad. Sci. USA 1989, 86, 4076. 
14 J. K. Ichida, A. Horhota, K. Zou, L. W. MaLaughlin, J. W. Szostak, Nucleic Acids Res. 2005, 33, 5219. 